\title{
O DESENVOLVIMENTO DA TEORIA SEMIÓTICA DE HUSSERL DE 1890 A 1901*
}

\author{
Daniel Peluso Guilhermino** \\ https://orcid.org/0000-0001-9636-5511 \\ dguilhermino@gmail.com
}

RESUMO $O$ artigo tem por objetivo analisar a mudança no regime do signo que ocorreu na filosofia de Husserl entre os anos de 1890 e 1901. Para tanto, partimos da reconstrução da teoria do simbolismo apresentada em Sobre a Lógica dos Signos (Semiótica), de 1890, e analisamos a recepção de algumas de suas teses centrais em Investigações Lógicas, de 1901. Querse, com isso, sublinhar a relevância histórica deste pequeno tratado de 1890 para a fenomenologia madura de Husserl. Ver-se-á, especificamente, que (1) a crítica ao princípio da economia do pensar apresentada em Prolegômenos à Lógica Pura é o prolongamento de uma tese de 1890 e (2) que o conceito de intenção simbólica vazia de 1901 é a resposta de Husserl aos impasses de sua primeira teoria do signo enquanto substituto. Conclui-se, por fim, mostrando como essa mudança no regime do signo é condição de possibilidade para a análise correlativa característica de Investigações Lógicas.

Palavras-chave Semiótica. Símbolo. Intuição. Representação. Husserl.

ABSTRACT The article aims to analyze the changes in the regime of sign that occurred in Husserl's philosophy between the years of 1890 and 1901. To do so, we start with the reconstruction of the theory of symbolism presented in On the Logic of Signs (Semiotics), from 1890, and analyze the reception of some of its central theses in the Logical Investigations, from 1901. It is

* Artigo submetido em 23/05/2019. Aprovado em 12/05/2020.

** Universidade de São Paulo. São Paulo, SP, Brasil. Bolsista da Fundação de Amparo à Pesquisa do Estado de São Paulo (FAPESP). Processo n²019/01444-6. 
intended to emphasize the historical relevance of this small treatise of 1890 for Husserl's mature phenomenology. It will be seen specifically that (1) the critique of the principle of the economy of thought presented in Prolegomena to Pure Logic is the extension of a thesis from 1890 and (2) that the concept of symbolic empty-intention from 1901 is Husserl's answer to the impasses of his first theory of the sign as a substitute. We conclude, in the end, by showing how this change in the regime of sign is condition of possibility for the correlative analysis characteristic of the Logical Investigations.

Keywords Semiotics. Symbol. Intuition. Presentation. Husserl.

"Como se pode falar de conceitos que não se tem propriamente (eigentlich)? E como não é absurdo que sobre tais conceitos a mais segura das ciências, a aritmética, deva ser fundada?" (Husserl, 1970, p. 142). ${ }^{1}$ Essa pergunta, que conclui o capítulo X da Filosofia da Aritmética (doravante $P A$ ), sintetiza a problemática diretora da primeira filosofia de Husserl. Trata-se, numa palavra, da reflexão acerca da legitimação do conhecimento não intuitivo. ${ }^{2}$ Nessa sua primeira obra, tal problemática aparece essencialmente vinculada ao projeto de fundamentação da matemática. Husserl parte do Faktum da aritmética - isto é, da constatação de que a aritmética funciona e é a ciência por excelência - e investiga, reflexivamente, suas condições filosóficas ${ }^{3}$ de possibilidade. Essa investigação tomará a forma de uma teoria genética do representar simbólico, teoria responsável por mostrar de que modo os procedimentos os mais abstratos da matemática despontam da experiência intuitiva ordinária de contar, e isso tão longe quanto pode ir a análise (ou cálculo, disciplina matemática que lida com funções limite, integração e derivação). É assim que $P A$ nada mais é que um primeiro capítulo no programa geral de aritmetização da análise, cujo objetivo último é demonstrar que a disciplina matemática mais elevada,

1 A menos que empregada edição brasileira (cf. Referências), todas as traduções são de responsabilidade nossa.

2 Alguns intérpretes, como Willard (1984, p. 84) e De Boer (1978, p. 68), sustentam mesmo que esse é o problema não somente da primeira fase, como da filosofia de Husserl como um todo.

3 Já desde sua Habilitationsschrift (Husserl, 1970, p. 291) Husserl compreende esse seu primeiro empreendimento como essencialmente filosófico. Essa compreensão se deve ao fato de Husserl se ancorar na psicologia descritiva de Brentano, que era tida por fundamento da filosofia (Brentano, 1924, p. 30). Ademais, como indica lerna, evidências recentes têm mostrado que "uma filosofia brentaniana da matemática já tinha lugar quando Husserl começou a trabalhar em sua habilitação e em seu primeiro livro” (lerna, 2017, p. 148). 
o cálculo, funda-se na aritmética - mostrando, portanto, que seu domínio conceitual é também a experiência ordinária (intuitiva) do número enquanto aquilo que pode ser contado.

Ora, uma teoria geral do símbolo é, naturalmente, indispensável para esse empreendimento geral de fundação do cálculo. Tal teoria, todavia, não se faz presente em $P A$. Ao mostrar de que modo as operações básicas da aritmética remetem, em última instância, à experiência intuitiva ordinária de contar, Husserl não problematiza, ali, a natureza e função dos símbolos que compõem tais operações básicas. É assim que, nessa obra, o símbolo é compreendido como substituto (Ersatz), ou sucedâneo (Surrogat), das coisas, sem que se extraia maiores implicações dessa compreensão.

O esclarecimento dessa função de substituição do símbolo, todavia, não escapa à reflexão de Husserl, sendo antes o principal objetivo do texto intitulado Sobre a Lógica dos Signos (Semiótica) (doravante Semiótica), de 1890. Este texto, planejado para o nunca publicado segundo volume de $P A,{ }^{4}$ apresenta o primeiro esboço de uma teoria do simbolismo em Husserl. É nele que encontramos seus primeiros esforços de uma clarificação psicológica e lógica do uso de símbolos, o que se dá em conjunto com uma primeira tentativa de caracterização das especificidades da consciência intuitiva e sua distinção do pensamento discursivo.

Este pequeno texto, que até pouco tempo despertava pouco interesse na literatura secundária, ${ }^{5}$ mostra-se de inegável valor para a compreensão de certas ideias chaves da fenomenologia madura. Como aponta Majolino (2012), é ele que lança as bases das reflexões husserlianas posteriores sobre o signo. Nosso objetivo, neste artigo, será o de explorar tais bases a partir da análise da recepção de duas teses centrais de Semiótica em Investigações Lógicas (doravante $L U$ ). Nomeadamente, veremos (1) que a crítica ao princípio da economia do pensar de Mach e Avenarius que Husserl elabora no $\$ 56$ de Prolegômenos à Lógica Pura (doravante Prolegômenos) provém de uma das principais teses da Semiótica; e (2) que a crítica à teoria do signo desenvolvida na $1^{\mathrm{a}}$ Investigação Lógica é o

4 Husserl desiste da elaboração do segundo volume de $P A$ porque abandona, ainda no período de publicação do primeiro volume, a ideia central que presidiu todo o projeto - a saber, a ideia de que a aritmética se funda no conceito de número (Husserl, 1956, p. 294). A primeira expressão desse abandono aparece na carta a Stumpf de 1890 (Husserl, 1983, p. 248), em que Husserl apresenta sua nova concepção de aritmética como arte dos signos (Kunst der Zeichen). Para uma exposição dessa virada na primeira filosofia de Husserl, ver Miller (1982). A se levar em conta a datação de lerna (2005), o texto da Semiótica foi escrito exatamente depois da carta a Stumpf. Willard (1980), todavia - e Hopkins (2002), seguindo Willard -, sugere que sua redação se deu mesmo antes da carta a Stumpf.

5 O caráter ambíguo do texto justifica, em parte, que se o tenha considerado de pouca importância para as concepções maduras de Husserl referentes ao representar simbólico. Um dos primeiros a chamar atenção a ele foi Willard $(1980,1994)$. Recentemente, porém, o trabalho de comentadores tem comprovado, cada vez mais, sua relevância histórica. É o que mostram os trabalhos de lerna (2003), Schuhmann (2005), D'Angelo (2013), Majolino (2010, 2012), Zuh (2008, 2012) e Byrne (2017a, 2017b, 2017c, 2018). 
resultado de uma evolução na concepção husserliana de signo, especificamente com relação à concepção apresentada em Semiótica.

Por se tratar de um texto pouco conhecido, iniciamos, na primeira seção, com uma análise geral da teoria do símbolo ali apresentada. Começamos por contextualizar sua problemática, explicitando o caráter das investigações de Husserl de então (seção 1.1) e, em seguida, reconstruímos a classificação geral dos símbolos que é ali apresentada (seção 1.2). Posteriormente, analisamos a teoria que o texto defende como via de legitimação dos símbolos que operam como substitutos cômodos (seção 1.3), e a legitimação lógica para o processo psicológico de operações simbólicas em geral (seção 1.4). Na seção 2, apresentamos a relação de uma de suas teses centrais com a crítica ao princípio da economia do pensar dos Prolegômenos (seção 2.1) e com a crítica à teoria do signo da $1^{\text {a }}$ Investigação Lógica (seção 2.2). Concluímos, por fim, indicando como a crítica apresentada em 2.2 torna possível a análise correlativa característica da fenomenologia de $L U$ (seção 3).

\section{A teoria do símbolo em Sobre a Lógica dos Signos (Semiótica) de 1890}

1.1. Em que sentido se diz das investigações de Husserl que são 'lógicas'?

Os subtítulos das duas primeiras grandes obras de Husserl trazem a expressão 'investigações lógicas'. ${ }^{6} \mathrm{O}$ que significa, porém, qualificar uma investigação como lógica? Tal pergunta exige uma análise do sentido específico que 'lógica' adquire em Husserl. Já na introdução à sua Habilitationsschrift, ${ }^{7}$ de 1887, Husserl classifica a lógica moderna como uma disciplina que, em contraste com a lógica 'antiga', compreendeu sua verdadeira tarefa como "aquela de uma disciplina prática (aquela de uma tecnologia [Kunstlehre] do juízo correto)", sendo um de seus principais objetivos aquele de ser uma "teoria geral dos métodos das ciências" (Husserl, 1970, p. 291). Isso que Husserl chama de lógica 'moderna' é, na verdade, como enfatiza Willard, uma espécie de concepção particular sua (Willard, 1979, p. 145). ${ }^{8}$ Segundo essa concepção, a arte (Kunst) da qual a lógica deve ser a teoria (Lehre) é a atividade natural do pensamento científico. Tratase dos raciocínios que acompanham toda investigação científica, raciocínios cuja característica central é aquela da derivação de certas verdades a partir de

"Filosofia da Aritmética: Investigações Psicológicas e Lógicas" (1891) e "Investigações Lógicas" (1900/01). Über den Begriff der Zahl. Psychologische Analysen. O texto completo de sua Habilitationsschrift compõe, "quase que palavra a palavra" (Husserl, 1970, p. 8), os 4 primeiros capítulos de PA.

8 Não tão particular assim, visto que ela foi inspirada nos cursos de lógica de Brentano. Cf. Brentano (1956). 
verdades já conhecidas. Numa palavra: a lógica nada mais é que uma teoria normativa responsável por orientar os raciocínios de que são compostas as ciências dedutivas.

Pode parecer que a lógica assim caracterizada comporte exclusivamente uma teoria pura da dedução. Não é esse, porém, o caso. A dedução é certamente parte das atividades lógicas do pensamento que compõem as ciências, mas não seu todo: "As ciências dedutivas (Die deduktiven Wissenschaften) não apenas inferem (schließen): elas também operam, constroem e calculam" (Husserl, 1979 , p. 6). Assim, a lógica deve ser uma teoria normativa com respeito a todas essas atividades. É essa separação entre dedução e as demais atividades lógicas que é a chave para que se compreenda o que há de específico na concepção de Husserl. Pois se temos, de um lado, dedução, e, de outro, cálculo, quer isso dizer que uma dedução não pode ser reduzida a um cálculo. O cálculo é, na verdade, um "sucedâneo externo (äußerliches Surrogat) da dedução (Folgerns)" (1979, p. 8). É uma técnica de manipulação de signos que pretende tornar supérflua a dedução, um algoritmo para derivação de signos sem significação a partir de outros signos também sem significação. Trata-se, na verdade, da degeneração da dedução em uma mera técnica de dedução, degeneração que ocorre já desde a escolástica (1979, p. 7). É fato que essa degeneração em mera técnica está na base do avanço extraordinário do cálculo lógico, que, por sua vez, está na base de muitas conquistas científicas. Esse avanço, não obstante, caminha junto com sua limitação enquanto linguagem simbólica, isto é, sua limitação enquanto espelhamento dos procedimentos dedutivos reais. Isso porque a sua consecução não exige um isomorfismo entre as operações simbólicas e as operações do pensamento; antes, basta que o ponto de partida e o ponto de chegada sejam interpretados, o resto podendo ficar a cargo do algoritmo cego $(1979$, p. 8). Ora, permanecendo em aberto a possibilidade de o cálculo não ser uma linguagem simbólica em pleno sentido, a pergunta que a lógica naturalmente deve se colocar com relação a ele é aquela que diz respeito à legitimidade de sua função de substituição da dedução. Eis a tarefa principal da lógica 'moderna' no sentido específico de Husserl: a tarefa de legitimar o cálculo lógico. ${ }^{9}$ Uma 'investigação lógica', portanto, é uma investigação que se volta exclusivamente para o cálculo simbólico realizado de maneira puramente mecânica e busca pela lógica do seu proceder, isto é, busca pela legitimidade da substituição de deduções atuais por deduções mecânico-simbólicas.

9 Husserl diz, na resenha de Schröder, que "a lógica algorítmica" é, de fato, "descendente direta da antiga lógica formal" (Husserl, 1979, p. 8). Suspeita-se, a partir dessa constatação, que a revolução proporcionada pela Lógica Matemática no século XX não o entusiasmaria tanto. 
Husserl não cansa de enfatizar, em seus primeiros escritos, que a ausência da justificativa e legitimação do cálculo lógico é uma das maiores deficiências das lógicas correntes de então. Não que tal tarefa fosse simplesmente negligenciada ou mesmo descuidada pelos lógicos. Que se veja, por exemplo, a primeira página das Vorlesungen über die Algebra der Logik de Schröder, na qual o autor sublinha logo de início que "A lógica [...] se ocupa com todas as regras cujo cumprimento aumenta o conhecimento da verdade" (Schröder, 1966, p. 1 apud Husserl, 1979, p. 4). Como diz Willard, "não importa quão 'formalista' o lógico possa ser, é sempre o caso que ele espera que os resultados de seu trabalho sejam aplicados ao pensamento atual" (Willard, 1979, p. 146). O erro, para Husserl, consistia em que tais lógicos procuravam a justificativa lógica do proceder do cálculo no interior das próprias regras do cálculo. Quanto a isso, sublinha Husserl que "o cálculo lógico é um cálculo (Kalkül) de dedução pura (reinen Folgerung), mas não a sua lógica" (Husserl, 1979, p. 8, grifo nosso). A investigação que pretenda inquirir a lógica do cálculo lógico deve se situar, por princípio, fora desse cálculo. Essa era, segundo Husserl, a cegueira dos lógicos 'extensionalistas'. Comentando o objetivo de Schröder de fornecer uma lógica da dedução, Husserl confessa que "dificilmente pode-se ficar mais decepcionado" com o cumprimento insatisfatório de tal objetivo, insistindo que tal decepção é "característica de toda lógica extensional" (1979, p. 5). Na verdade, não é de se espantar que lógicos excepcionais encontrem dificuldade em apresentar teorias suficientes com respeito à lógica de suas lógicas, uma vez que é já conhecido o fato de que "se pode ser um técnico extraordinário em lógica e ser um filósofo da lógica medíocre", do mesmo modo que "se pode ser um extraordinário matemático e um filósofo da matemática medíocre", sendo que "Boole oferece um ótimo exemplo de ambos" (1979, p. 9).

Mas se não se encontra a lógica do cálculo lógico no interior desse próprio cálculo, onde então encontrá-la? Em uma teoria do simbolismo, isto é, em uma semiótica. Como diz Porta, "uma teoria correta do cálculo está intimamente ligada a ou é parte de uma correta teoria do simbolismo em geral" (Porta, 2013, p. 29). Essa teoria geral do simbolismo Husserl busca elaborar tendo como horizonte o ideal de legitimação do cálculo simbólico aritmético a partir da teoria das representações impróprias de Brentano. A partir de Brentano, Husserl procura mostrar, em $P A$, de que modo as representações impróprias (uneigentliche) ou simbólicas (symboliche) que compõem a maior parte das operações aritméticas estão em relação de equivalência lógica com as representações próprias (eigentliche), o que tomava por pressuposto a ideia de que as representações simbólicas são capazes de substituir as próprias. Todavia, nada se dizia, ali, acerca das especificidades dessa função de substituição. 
Será essa a tarefa do tratado da Semiótica. Trata-se de preencher uma lacuna deixada por $P A$ e esclarecer a especificidade da função de substituição da coisa pelo símbolo. Antes desse esclarecimento, porém, cumpre realizar uma classificação geral dos signos. Essa classificação, como veremos a seguir, será decisiva para a própria caracterização da função de substituição que o texto oferece.

\subsection{Classificação dos símbolos e a relação entre símbolo e coisa}

O texto da Semiótica inicia sua abordagem do conceito de signo em um plano idêntico àquele de $P A$, resgatando a pergunta norteadora de suas investigações que já mencionamos: "Mas como é possível falar de conceitos que propriamente não temos, e como é que não é absurdo que sobre esses conceitos se funde a mais segura de todas as ciências, a aritmética?" (Husserl, 1970, p. 340). ${ }^{10}$ A distinção central que está por detrás dessa pergunta é, portanto, aquela mesma distinção brentaniana que diz respeito ao 'duplo modo' pelo qual as coisas podem nos ser dadas: de um modo próprio, como aquilo que elas são; ou de um modo impróprio ou simbólico, isto é, pela mediação de signos (Zeichen) (1970, p. 340). A distinção entre símbolo e coisa é, portanto, antes de tudo, uma distinção psicológica.

O conceito de signo é primeiramente tratado como conceito relacional: "para que o conceito de signo seja possível [...], temos de atender à relação entre signo e designado" (1970, p. 341). ${ }^{11}$ Para compreender como pode o signo se relacionar a algo outro, e como essa relação poderá ser lida como uma relação de substituição, cumpre reconstruir, primeiramente, a classificação dos signos elaborada por Husserl. Essa classificação tem sempre como norte o programa de aritmetização da análise de $P A$, o que faz com que muitas de suas distinções refiram-se a problemas de fundamentação da matemática. Segundo essa classificação, os signos distinguem-se em:

(a) Signos exteriores e conceituais. Signos conceituais são signos descritivos (umschreibenden) e marcas (Merkmale) do objeto, enquanto signos exteriores não descrevem, mas apenas designam (bezeichnen). Estes últimos Husserl denomina signos em sentido restrito (1970, p. 341). Exemplos de signos exteriores são os nomes próprios, enquanto exemplos de signos

10 Nas citações de Semiótica, utilizo a tradução de Fidalgo, disponível online (cf. Referências). Mantenho, todavia, o ano da edição da Husserliana, bem como a paginação desta última (também presente na tradução de Fidalgo).

11 No decorrer de suas análises, porém, Husserl se presta a uma classificação dos signos que o conduzirá forçosamente além da abordagem inicial do signo como mera designação, conforme veremos mais adiante. 
conceituais podem ser encontrados em quaisquer nomes que funcionem como caracterizadores.

(b) Signos simples (einfach) e compostos (zusammengesetzte) (1970, p. 343), que se cruzam com:

(c) Signos não ambíguos (eindeutige) e ambíguos (mehrdeutige). Os nomes próprios são não ambíguos por natureza, enquanto nomes gerais são, também por natureza e determinação intrínseca, ambíguos. Um nome próprio pode, apesar de sua não ambiguidade essencial, ser acidentalmente ambíguo, como quando o nome 'João' se refere a mais de um indivíduo. Já um nome geral, por sua vez, pode também ser não ambíguo de modo acidental, conquanto essencialmente ambíguo, "quando de fato existe apenas um objeto que cai sob o conceito por ele conotado" (1970, p. 342);

(d) Signos diretos e indiretos. Aos signos diretos corresponde a relação imediata entre signo e objeto designado, ao passo que aos signos indiretos corresponde a relação mediatizada por marcas características conceituais. Nomes próprios são exemplos de signos diretos, e nomes gerais, de indiretos. Nos signos indiretos é possível distinguir entre significação (Bedeutung) e designação (Bezeichnung), sendo a significação justamente essa co-designação ao objeto através de marcas características (1970, p. 343);

(e) Signos idênticos e não idênticos, equivalentes e não equivalentes (1970, p. 344). Signos idênticos são aqueles que designam o mesmo objeto do mesmo modo ('Napoleão' e 'Napoleão'), enquanto signos equivalentes são signos que designam o mesmo objeto mas de modo distinto (' $\mathrm{O}$ vencedor de Jena', 'O vencido de Waterloo'). A equivalência é proporcionada pela definição, que nada mais é que a expressão da significação de um signo exterior mediante um signo equivalente. Segue-se que um signo exterior direto, por designar seu objeto diretamente, e não através da significação, não é passível de definição (por exemplo os nomes próprios, o numeral 1, e nomes de entidades abstratas).

(f) Signos materiais e signos formais. Signos materiais são signos para conteúdos de representação, enquanto signos formais são signos para atos psíquicos. Conteúdos de representação são expressos por nomes, e podem se referir a conteúdos dependentes ou independentes, ou absolutos e relativos, que nada mais são do que a distinção da lógica clássica entre termos categoremáticos e sincategoremáticos (1970, p. 347). Atos psíquicos dizem respeito àquilo que se edifica sobre a base de conteúdos de representação, e.g., juízos. Essa distinção é particularmente importante para clarificar a natureza do juízo. Nas concepções clássicas de juízo como síntese de representações, confundia- 
se o ato do juízo com a forma da relação. Husserl, seguindo Brentano, compreende o juízo não como síntese de representações, mas como aceitação (Annehmen) ou rejeição (Verwerfen) de um conteúdo. Com a distinção entre signos formais e materiais, pode-se, então, compreender que a síntese de representações é resultado de operações de termos sincategoremáticos, isto é, é um signo material, um conteúdo do juízo, e não o próprio ato de julgar. $^{12}$

Partindo dessa classificação, Husserl poderá, então, concentrar-se nas especificidades da relação entre signo e coisa. A função de designação que Husserl atribui ao signo é agora explicitamente denominada função de substituição (Stellvertretung). Esta pode ser dada de dois modos:

(1) Indiretamente. É o caso de "emblemas convencionais, sequências verbais mnemotécnicas, versos decorados mecanicamente etc.” (1970, p. 351). O princípio explicativo da substituição indireta reside na motivação: a existência de tais signos motiva-me a representar seus respectivos objetos designados. Um exemplo é a fumaça como signo de fogo, ou a bandeira como signo da nação.

(2) Diretamente. Esse modo de substituição comporta uma ulterior distinção: (2.1) Substitutos cômodos. Trata-se de representações simbólicas que substituem coisas ou estados de coisas passíveis de verificação, isto é, que podem ser intuídas. Essas coisas e estados-de-coisas são geneticamente primárias em relação ao símbolo, isto é: primeiro vejo a coisa, depois a simbolizo. A simbolização ocorre devido a uma lei natural intrínseca à nossa atividade cognitiva, a saber: a lei da economia do pensar que poupa uma atividade psíquica superior. Assim, esses signos são representações simbólicas que servem de substitutos cômodos às próprias. Como diz Husserl, é mais fácil e menos dispendioso representar um conteúdo mais concreto do que um mais abstrato; fantasiar do que sentir; representar um conteúdo singular do que um múltiplo; representar conteúdos primários do que psíquicos etc. (1970, p. 352).

12 No $\S 51$ da $6^{a}$ Investigação, pode-se ver a compreensão dos signos sincategoremáticos como uma "relação intencionalmente unitária" que é dada em atos de intuição categorial (Husserl, 2007, p. 689). A raiz dessa concepção encontra-se nessa distinção entre signos materiais e formais da Semiótica. Todas as citações de LU seguem a paginação original da Husserliana, também presente nas edições brasileiras e portuguesas aqui utilizadas. 
(2.2) Substitutos necessários. Trata-se de representações impróprias que substituem coisas ou estados-de-coisas que não são passíveis de verificação, isto é, que não podem ser intuídas. Sua simbolização é, portanto, não um caso de comodidade, mas de necessidade: não são "signos ou abreviaturas para as representações próprias originais e a cada momento fáceis de reproduzir" (1970, p. 354). Os símbolos reportam-se, ao contrário, "a coisas cuja representação própria nos é interdita, seja temporariamente, seja permanentemente" (loc. cit.). A interdição permanente pode ser proveniente dos limites da nossa determinação fática, como ocorre com os conceitos de 'África', 'Terra', o conceito de 'homem' no sentido da fisiologia ou da psicologia etc. Nesses casos, por mais que os astrofísicos façam afirmações sobre a Terra, jamais poderão vê-la no seu todo. Nada nos impede, todavia, de conceber um ser que possa, pela sua capacidade de percepção superior à nossa, contemplar a Terra no seu todo na intuição (Husserl, 1970, p. 356). Também pode ser o caso da interdição principialmente permanente, como é o caso com conceitos contraditórios tais como 'quadrado redondo' ou 'ferro de pau', ou conceitos extra psíquicos tais como 'Deus', 'coisa exterior' ou 'alma de um outro'. Os conceitos contraditórios são necessariamente simbólicos porque comportam a união impossível de duas ou mais marcas características; o conceito de coisa exterior e alma de um outro são considerados irrepresentáveis por Husserl em função de seu caráter extra-psíquico. Já o conceito de Deus tem como um de seus atributos o conceito de perfeição infinita, que demandaria uma capacidade psíquica atualmente infinita, "a nós de todo incompreensível" (loc. cit.). Nesses casos, nem mesmo seres com capacidades cognitivas superiores às nossas teriam condições de superar o simbolismo inerente a tais representações.

Com essa subdivisão entre substitutos cômodos e necessários damos um passo além da concepção de signo como mera designação com a qual iniciamos. Agora, temos claramente diante dos olhos os signos que fazem as vezes de seus referentes e os signos que efetivamente os substituem. A abordagem de signos cuja interdição aos seus designados é principialmente permanente é uma posição teórica intermediária de Husserl. Se, de um lado, tais signos não se faziam presentes em $P A$, de outro, seu modo de compreensão é criticado na já mencionada carta a Stumpf como ainda pertencente ao prejuízo inicial da função de substituição. Em uma passagem da carta, diz Husserl: 
"Uma vez que originalmente considerei os signos somente em relação aos conceitos designados, no caso de números cardinais tais como $\sqrt{ } 2, \sqrt{ }-1$ etc., por exemplo, tive que tomá-los como representativos de conceitos "impossíveis" (Husserl, 1983, p. 247). É exatamente essa a caracterização dos substitutos necessários principalmente permanentes da Semiótica: eles são ainda substitutos de coisas, ainda que de coisas impossíveis. O foco de Husserl ainda é o do lado objetivo da relação símbolo/coisa, e por isso a abordagem de tal relação passa por uma complicação na estrutura do objeto, mediante a categorização de diferentes estratos ontológicos de designação dos signos, isto é, diferentes regiões conceituais às quais os signos se aplicam de modo designativo. Uma dessas regiões seria a região dos objetos impossíveis, à qual corresponderiam, no plano simbólico, os substitutos necessários de interdição permanente. ${ }^{13}$

Feita essa súmula do que Husserl tem a dizer, na Semiótica, acerca do signo e de suas funções, podemos deixar o plano psicológico de análise e passar àquele que diz respeito a uma efetiva lógica dos signos. São estas investigações lógicas, que se apresentam em ziguezague no texto, que plantarão várias sementes da fenomenologia madura. Podemos identificar dois níveis dessas investigações lógicas. Primeiramente, temos uma investigação que busca justificar o uso dos substitutos cômodos, isto é, legitimar logicamente a utilização daqueles signos cujos objetos designados estão disponíveis para verificação. Em um segundo nível, temos uma autêntica justificativa lógica dos procedimentos algoritmos simbólicos como um todo, explicando como o cálculo cego com símbolos pode levar à verdade. Vamos examinar cada um desses níveis antes de analisar, na seção 2, como cada um deles deságua em $L U$.

\subsection{O primeiro nível de investigação lógica da Semiótica: A legitimação} lógica dos substitutos cômodos

O primeiro nível da investigação lógica da Semiótica para o problema da legitimação do pensamento simbólico é aquele que diz respeito aos substitutos cômodos, isto é, aos signos cuja remissão ao objeto designado é possível. Husserl

13 Convém ressaltar a enorme importância da introdução desses signos para diversos pontos da filosofia madura de Husserl. lerna (2003) mostra de que modo a introdução desses substitutos de interdição permanente oferecem, pela primeira vez, as condições para a abordagem husserliana do conceito de infinito. Se nos mantivéssemos com as ferramentas de $P A$, estaríamos condenados a uma concepção psicologista de infinito; agora, com o conceito de símbolos necessários de interdição permanente da Semiótica, temos a possibilidade de símbolos que não são meras idealizações de representações próprias, o que permite uma correta apreciação do conceito de infinito. Zuh (2008) chama atenção para esses conceitos "misteriosos" e como eles representam uma primeira tentativa de Husserl de capturar a consciência de horizonte que desempenhará um papel fundamental nas análises genéticas tardias. Schuhmann (2004) enfatiza de que modo a introdução desses símbolos permite Husserl ir além das concepções de símbolo de Brentano e Stumpf, na medida em que desatrela a consciência simbólica da finitude humana. 
se pergunta: "Como é possível que estes sucedâneos extremamente pobres e, em parte, intrinsecamente estranhos ao verdadeiro conceito das coisas, possam contudo substituir estes e servir de fundamento aos juízos, às volições, etc. que sobre eles incidem?" (Husserl, 1970, p. 352). Em outras palavras: como podem os símbolos se referir às coisas? A resposta é como segue:

Devido ao fato de que os signos, que fazem-as-vezes-de (e que em relação à mesma coisa se alteram de momento a momento), ou encerrarem em si as marcas características, em que cai o interesse momentâneo, como conteúdos parciais ou então, pelo menos, possuírem a aptidão de servir como os pontos de partida e de ligação de processos ou atividades psíquicos que conduziriam a essas notas características ou mesmo aos conceitos plenos e que nós, sempre que necessário, podemos provocar e produzir (1970, pp. 352, 353).

Explicitemos. ${ }^{14}$ Estamos habituados a utilizar a palavra 'livro para nos referir ao objeto que conhecemos como livro. Como posso, não tendo o livro diante de mim, referir-me a ele de modo justificado, isto é, como posso saber que a palavra "livro" vai sempre se referir àquele objeto precisamente ao qual ela se refere? Quando faço, por exemplo, um juízo sobre um livro que comprei sem tê-lo à vista no momento, como então estou certo de que essa operação com palavras se refere precisamente ao objeto ao qual pretendo que ela se refira? Ou, citando a primeira frase da Semiótica, "como se pode falar de conceitos que não se tem propriamente?” (1970, p. 340). Segundo Husserl, a resposta reside no fato de que o signo linguístico 'livro' serve como ponto de partida para a produção das marcas características do objeto livro. Com a palavra livro surge, imediatamente, na corrente dos meus pensamentos, uma imagem retangular que representa uma aproximação grosseira com o objeto verdadeiro. Essa imagem tosca basta para garantir que estamos lidando com um substituto legítimo da coisa. Byrne fala em uma "espécie de identificação errônea" (a kind of misidentification) que seria a responsável pela conexão entre símbolo e coisa (Byrne, 2017b, p. 215). O signo deve ou encerrar as marcas características dos objetos verdadeiros (no caso dos substitutos diretos) ou servir como ponto de partida que conduz a essas marcas características (no caso dos substitutos indiretos). Em suma, estamos justificados em operar com signos em vez de coisas se, e somente se, formos capazes de produzir representações acompanhantes (Begleitvorstellungen) que nos assegurem essa conexão entre símbolo e coisa: 
Esta representação acompanhante (Begleitvorstellung), cuja nota característica apresenta uma tosca aproximação ao conceito intendido e mediante isso o simboliza, pode desaparecer então de novo, ficando a simples palavra; mas o seu surgimento bastou para nos assegurar a familiaridade com a coisa (Husserl, 1970, p. 353).

1.4. O segundo nível de investigação lógica da Semiótica: O princípio da economia do pensar e o processo lógico paralelo ao psicológico

O segundo nível da investigação lógica é aquele que se volta para uma justificação dos processos envolvendo símbolos, isto é, dos juízos e raciocínios contendo símbolos. O que se deve explicar agora é a legitimidade lógica das operações do pensamento que nos conduzem de um símbolo a outro, uma vez que a lei psicológica/natural responsável pela condução de tais operações é a lei cega de associação de ideias cujo princípio regente é a minimização do esforço, qual seja, a lei da economia do pensar (1970, p. 355). Ou seja, do ponto de vista psicológico, nos nossos raciocínios e cálculos simbólicos "procedemos sem qualquer justificação, não nos guia um motivo gnosiológico, mas sim um mecanismo psicológico" (1970, p. 358).

Husserl distinguirá duas classes principais de casos nas quais a clarificação desses processos deverá ser dada. A primeira classe diz respeito às concatenações de símbolos que encerram juízos próprios, isto é, juízos que "só possu[em] um caráter simbólico, aliás não particularmente notório, visto a matéria ajuizada consistir em substitutos em vez de representações próprias" (1970, p. 359). Para esses casos, a justificação lógica de seu proceder segue a mesma explicação do uso de símbolos cômodos que analisamos acima: trata-se do fato de os signos sobre os quais se julga conterem, neles próprios, as partes e marcas dos conceitos reais (wirklichen). Assim, "um juízo liga-se exclusivamente a um objeto $\mathrm{X}$ na medida em que X possui a marca A; G possui a marca A; logo o juízo também é válido para G, precisamente sob o mesmo ponto de vista" (1970, p. 360).

A segunda classe considerada por Husserl é aquela em que os juízos são eles mesmos impróprios, "na medida em que signos exteriores, por exemplo, proposições ou complexos proposicionais sistemáticos, substituem juízos e raciocínios" (1970, p. 359, tradução modificada). É o caso do cálculo aritmético. Nele,

não nos agarramos a conteúdos próprios e plenos, nem a conteúdos parciais substitutos, mas simplesmente a nomes ou letras, de modo que não podemos falar eo ipso de um ajuizar ou raciocinar próprios. Mecanicamente vamos ao longo da cadeia, ligamos e eliminamos elementos, como o exige o modelo, e obtemos assim um juízo simbólico (uma proposição), que nos serve de signo de uma verdade (1970, p. 361). 
O cálculo aritmético tal como descrito acima é utilizado, pelos matemáticos, sem qualquer consciência lógica do seu proceder. Isto é, trata-se de uma utilização essencialmente prática dos signos, exercida de modo mecânico e assentada no hábito. A aritmética geral, segundo Husserl, "com seus números negativos, irracionais e imaginários ('impossíveis'), foi inventada e aplicada durante séculos antes de ser compreendida" (1970, p. 370). Também nas ciências naturais "os investigadores utilizam com um sucesso extraordinário estes métodos, sem se sentirem constritos pela própria falta de clareza, ou pela da dos lógicos, sobre sentido, limites e valor cognitivo dos mesmos" (loc. cit.). Em suma, trata-se, em todas essas operações de grau mais elevado, de uma utilização pré-lógica de signos. Essas operações são guiadas única e exclusivamente pela lei natural cega da associação de ideias, uma vez que "a origem dos métodos artificiais reside nos naturais" (Husserl, 1970, p. 366).

Em regra, essa lei cega de associação de ideias nos conduz a resultados certos, isto é, à verdade, e "isto é um fato metafisicamente muito interessante" (1970, p. 358). Isso faz com que ela comporte uma espécie de teleologia aparente, isto é, com que ela pareça conduzir as operações simbólicas à produção e ampliação de conhecimento. Em que pese sua direção correta na maioria dos casos, tais processos naturais podem ainda levar a erros em casos específicos, sendo por isso necessária uma garantia lógica de sua certeza (1970, pp. 365, 366).

Levando-se tudo isso em consideração, a estratégia de Husserl para justificar a utilização pré-lógica dos signos será a de criar um mecanismo lógico paralelo ao psicológico que seja, este sim, projetado explicitamente para a produção e ampliação de conhecimento e livre de qualquer possibilidade de erro. Em seguida, bastará medir o processo natural cego pelo processo lógico propositadamente elaborado e certificar-se, assim, da lógica de seu proceder.

A criação do mecanismo lógico paralelo ao psicológico segue os seguintes passos. Deve-se estabelecer uma correspondência unívoca entre as "ligações sistemáticas das palavras" e "as do pensamento", e a "reprodução da conclusão deve poder realizar-se com base unicamente nas premissas" (1970, p. 364). Assim, conclui Husserl,

a univocidade da expressão linguística e a determinação unívoca da conclusão pelas premissas, tanto pelo lado psíquico como pelo simbólico - isso são exigências necessárias e suficientes para o processo mecânico cego, por um lado, e para o processo lógicomecânico, por outro (1970, p. 364).

Vemos, então, que, não obstante a introdução, no texto da Semiótica, de uma subdivisão ausente em $P A$ - aquela que nos oferece substitutos necessários que não contam com a possibilidade de realização intuitiva -, o esquema geral 
de ambos os textos continua o mesmo. Isso porque a semiótica desse pequeno tratado, embora assentada em um universo simbólico mais rico, segue o mesmo roteiro que presidiu o projeto anterior de aritmetização da análise de $P A$, qual seja: encontrar um modo de garantir o paralelismo estrito entre o simbólico e o intuitivo. Isso se deve principalmente ao prejuízo do símbolo enquanto substituto mencionado na carta a Stumpf. O foco ainda é aquilo que o signo designa, seu lado 'real', 'objetivo', e não o signo mesmo, o signo 'enquanto signo'. Um bom tempo deverá passar até Husserl se dar conta de que uma solução para o problema do imaginário em termos ‘objetivistas' é simplesmente impossível. ${ }^{15}$

\section{A recepção da Semiótica de 1890 nas Investigações Lógicas de 1901}

\subsection{A crítica ao princípio da economia do pensar nos Prolegômenos}

Podemos agora, finalmente, analisar de que modo esses dois níveis de investigações lógicas da Semiótica se fazem presentes em $L U$. Começaremos pelo modo como o segundo nível de investigação lógica da Semiótica (1.4 acima) aparece na crítica que Husserl dirige a Mach e Avenarius nos Prolegômenos.

English afirma que o texto da Semiótica pode ser considerado "de longe o mais psicologista que Husserl já escreveu", psicologismo este que seria constatado sobretudo na defesa da "atitude que o capítulo IX dos Prolegômenos fez minuciosamente a crítica, denunciando o "princípio da economia do pensamento' do qual deve depender a lógica” (English, 2010, p. 89). Ora, Husserl não defende, na Semiótica, o princípio da economia do pensar como base da lógica. Antes, apenas o estabelece como o motivador natural para o processo de simbolização. Essa será, também, a tese dos Prolegômenos. A crítica a tal princípio, ali, segue exatamente o mesmo roteiro da Semiótica: ele se torna criticável quando deixa de ser uma doutrina de fato e é considerado uma lei. A única diferença é que, em 1890, Husserl trabalhava com a distinção entre o plano 'psicológico' e o 'lógico', e, em 1900, com a distinção entre 'doutrinas de fato' e 'leis ideais'.

15 Ainda nas lições de lógica de 1896 Husserl continua a se valer da ideia de um paralelismo entre o simbólico e o conceitual como via de legitimação do cálculo simbólico: "a cada derivação correta (regelrechten Herleitung) assim corresponde um resultado que, quando interpretado conceitualmente, leva a uma proposição correta. Isso se deve ao preciso paralelismo entre operações mentais e operações com signos" (Husserl, 2001, pp. $247,248)$. Somente na Doppelvortrag, dada a convite de Hilbert à Sociedade Matemática de Göttingen em novembro e dezembro de 1901, poder-se-á ver uma solução que prima pelas leis internas ao algoritmo simbólico, independentemente de seu paralelismo estrutural ao real (cf. Husserl, 1970, pp. 430-451). 
Evidência de que a tese de Husserl, nos Prolegômenos, é mero desdobramento da ideia plantada na Semiótica se deixa ver na sua concessão ao princípio da economia do pensar dentro de seus limites factuais:

A doutrina de Mach da economia do pensar, assim como a de Avenarius, do dispêndio mínimo de energia, refere-se [...] a certos fatos biológicos, tratando-se, pois, de uma ramificação da teoria da evolução. É, nestes termos, óbvio que pelas pesquisas aqui em causa pode, com efeito, ser lançada luz sobre a doutrina prática do conhecimento, sobre a metodologia da pesquisa científica mas, de modo nenhum, sobre a doutrina pura do conhecimento e, especialmente, sobre as leis ideais da lógica pura" (Husserl, 2014, p. 206).

A estratégia argumentativa dos Prolegômenos contra esse princípio é, assim, rigorosamente a mesma que a do texto da Semiótica: trata-se da crítica da utilização de doutrinas de fato para justificar verdades de razão. Na Semiótica, o que motivava a criação do processo lógico paralelo era justamente a constatação de que o plano psicológico do princípio da economia do pensar nada justifica. Antes, ele apenas esclarecia a utilização pré-lógica dos signos. A insuficiência desse esclarecimento pré-lógico para fins de conhecimento é o que motivava, então, a criação de um processo lógico paralelo. Uma vez elaborado esse processo, bastaria medir o processo psicológico natural pelo lógico artificial e confirmar a validade do primeiro pelo último. Ora, diz Husserl, nos Prolegômenos, que "medimos o pensar empírico pelo ideal e constatamos que o primeiro, até certo ponto, decorre, de fato, como se fosse intelectivamente conduzido pelos princípios ideais" (Husserl, 2014, p. 211, grifo nosso), o que corresponde à estratégia da Semiótica de se direcionar ao processo natural-psicológico e autenticar sua verdade mediante sua correspondência ao mecanismo lógico construído propositadamente com fins cognitivos. Trata-se, numa palavra, da distinção entre o domínio natural de investigação e o domínio epistemológico. O primeiro explica causalmente; o último justifica logicamente.

Se, ainda assim, a teoria dos signos da Semiótica pode ser considerada psicologista, esse psicologismo deve ser localizado em outro lugar. Esse lugar é aquele do primeiro nível de investigação lógica relacionado aos substitutos cômodos (seção 1.3). É a partir desse nível que poderemos ver, ademais, a principal mudança na concepção de simbólico que se deu na filosofia de Husserl entre 1890 e 1901.

\subsection{A crítica à teoria do símbolo na $1^{a}$ Investigação Lógica}

É no segundo capítulo da $1^{\mathrm{a}}$ Investigação que se pode ver a segunda recepção da Semiótica em $L U$. Desta vez, no entanto, essa recepção se dará não em forma de um desdobramento, mas de uma crítica. O tema deste capítulo é a 
crítica da doutrina que "põe toda a performance da expressão significativa viva no despertar de certas imagens da fantasia que lhe estariam constantemente agregadas" (Husserl, 2012, p. 67). Essa doutrina, como veremos, é precisamente a doutrina defendida na Semiótica.

Husserl examinará a fundo essa doutrina e trará à tona suas imprecisões e inconsequências. Inicia-se tal exame pela seguinte fixação da tese defendida por ela:

Compreender uma expressão quereria dizer, de acordo com essa concepção, encontrar as imagens correspondentes da fantasia. Onde elas faltassem, as expressões seriam destituídas de sentido. Não raramente, ouvimos estas imagens da fantasia serem caracterizadas como sendo, elas próprias, as significações das palavras; e, decerto, com a pretensão de se ir ao encontro do que, no discurso corrente, se compreende como significação da expressão (2012, p. 67).

Antes de tudo, cumpre distinguir duas teses que a concepção a ser criticada defende: a compreensibilidade da expressão a partir das imagens da fantasia e a identificação dessas imagens com a própria significação. Trata-se de teses distintas. Atribuir a compreensão da significação de uma expressão à produção de imagens na fantasia não implica identificar tais imagens à significação. Ainda que não se diga que a significação é a imagem, pode-se defender que tal significação não é 'captada' senão por meio de imagens na fantasia.

Pois bem, Husserl se volta contra essas duas teses. Primeiramente, por mais que seja óbvio que as expressões linguísticas sejam, na grande maioria dos casos, acompanhadas por representações na fantasia, não são essas representações, porém, que as tornam compreensíveis, isto é, "não é a sua existência que constitui o valor significativo (Bedeutsamkeit) da expressão (ou até mesmo a sua própria significação), e [...] a sua falta não pode obstar a este valor (2012, p. 68, grifo nosso). Nosso destaque em itálico mostra a distinção que apresentamos acima: uma coisa é a imagem como constituindo o valor significativo da expressão, outra é a imagem como sendo a própria significação.

Insistimos nessa distinção pois o texto da Semiótica defenderá a primeira concepção, mas não a segunda. É apenas a ideia segundo a qual a compreensibilidade da expressão reside nas representações acompanhantes da fantasia - ou seja, na concepção de que nelas reside o valor significativo da expressão - que está presente naquela primeira doutrina dos signos de Husserl. Quer isso simplesmente dizer que não há, na Semiótica, uma teoria da significação propriamente dita. ${ }^{16}$

16 Aqui nos afastamos da análise de Byrne, que defende que há, em Semiótica, uma "teoria da significação imagética" (Byrne, 2017b, p. 224). Não há no texto a identificação da representação acompanhante com a 
Citemos os trechos decisivos de 1890 para esse esclarecer ponto:

Esta representação acompanhante, cuja marca apresenta uma tosca aproximação ao conceito intendido e mediante isso o simboliza, pode desaparecer então de novo, ficando a simples palavra (das bloße Wort); mas o seu surgimento bastou para nos assegurar a familiaridade com a coisa. (Husserl, 1970, p. 353, grifo nosso).

[...] se a memória nos abandona (im Stich läßt), de imediato acaba a compreensão, os símbolos não alcançam o seu objetivo, a corrente dos pensamentos para, e então damo-nos conta nós mesmos de que nos faltam os conceitos verdadeiros (1970, p. 353, tradução modificada, grifo nosso).

A crítica que Husserl agora direcionará a essa concepção não é tanto um contra-argumento, mas mais um novo enfoque. Os fatos continuam os mesmos: as expressões são acompanhadas por representações acompanhantes fugidias que podem mesmo desaparecer, restando somente o lado físico da expressão. Mesmo na Semiótica, como podemos ver na primeira citação acima, o desaparecimento da representação acompanhante não é acompanhado do desaparecimento do sentido: ainda quando finda a representação acompanhante, permanecemos compreendendo a expressão, precisamente devido àquele seu aparecimento anterior. A compreensão da expressão só acaba quando a representação não aparece em momento algum, como no caso relatado na segunda citação, quando 'a memória nos abandona'.

Agora, na $1^{\text {a }}$ Investigação, duas linhas argumentativas serão direcionadas contra essas duas concepções acima. Primeiro, Husserl dirá simplesmente que "[se] o seu [da expressão] sentido completo, vivo, continua ainda a se manter depois da desaparição da imagem", então, "por consequência, a compreensão não pode residir precisamente nessa imagem" (Husserl, 2012, p. 69). Basicamente, o que está sendo dito é que nossas representações acompanhantes são fugidias, enquanto a significação é permanente; logo, não pode ser essa multiplicidade variegada de representações aquilo que constitui o valor significativo da expressão.

Ora, e quanto ao caso da ausência completa de representações acompanhantes, como quando 'a memória nos abandona'? Husserl não faz uma crítica direta a esse caso específico, mas sua resposta pode ser vislumbrada nas entrelinhas de dois argumentos.

significação. A única referência à significação que Husserl faz ali é em relação aos signos indiretos, quando afirma que um signo indireto designa a coisa mediante a significação. Assim, a significação de um signo indireto $S$ é que ele designa o objeto $O$ através de uma série de signos que devem ser suficientes para o designar univocamente (Husserl, 1970, p. 343). Ora, se a significação se reduzisse à representação acompanhante, a designação não poderia ocorrer, uma vez que a equivocidade da significação impediria a univocidade da designação. 
Primeiramente, na crítica à teoria das imagens inconscientes. Tal teoria defende que quando compreendemos expressões sem imagens na fantasia, é porque tais imagens estão lá, mas de modo imperceptível. Husserl se pergunta se não é um contrassenso dizer que um momento da vivência é notado (a saber, o momento da "consciência da representação da fantasia", porquanto se diz que ela existe), enquanto a vivência no seu todo (a representação da fantasia concreta) não é (2012, p. 69); como se fosse possível saber que se vive algo e, ao mesmo tempo, não viver tal algo. Ora, sempre que eu vivo algo, sei, com absoluta evidência, que vivo este algo. Mas como pode ser o caso em que não vivo algo e, ao mesmo tempo, sei que vivo tal algo? Uma contradição clara.

$\mathrm{O}$ argumento mais forte, porém, e aquele que mais facilmente pode ser aplicado ao caso da falha de memória, é o referente às expressões absurdas. Nesses casos, como com as expressões "ferro de pau", "quadrado redondo" etc., "a inotabilidade não pode basear-se nas contingências das forças psíquicas, mas, pelo contrário, a imagem não pode, em geral, existir, porque, senão, ela garantiria com evidência a possibilidade do pensamento respectivo" (2012, pp. 69, 70). Expressões desse tipo são plenamente compreendidas sem que lhes corresponda qualquer imagem ou qualquer representação acompanhante que (seguindo a linguagem da Semiótica) ofereça uma 'aproximação tosca' com a significação em questão.

Numa palavra, a doutrina da $1^{\text {a }}$ Investigação inviabiliza a utilização de qualquer tipo de representação acompanhante como aquilo que torna compreensível a expressão. Isso é devido à clarificação das complexas relações entre intenção signitiva e intuição preenchedora proporcionada por $L U$, que conta, agora, uma teoria completa da intencionalidade (ausente em Semiótica). Ora, se as representações acompanhantes, que são imagens, fossem aquilo que garantisse a legitimação do símbolo, então essa legitimação se daria por um tipo de intuição. Em sendo um tipo de intuição, seria imbuída do sentido preenchedor (erfüllende Sinn), que, como ensina a $1^{\mathrm{a}}$ Investigação, não é sentido de modo originário, mas apenas derivado. ${ }^{17}$ Quando Husserl diz, portanto, na Semiótica, que a condição de possibilidade de utilização de signos para se referir às coisas reside na representação acompanhante que atua como uma 'espécie de identificação errônea' com a coisa mesma, está dizendo que $o$ valor significativo do símbolo reside em algo que é desprovido de sentido, pois que se trata de uma intuição. ${ }^{18}$

17 "continuaremos [...] a entender por significação pura e simples aquela significação que, enquanto elemento idêntico da intenção, é essencial à expressão enquanto tal" (2012, p. 58).

18 Essa crítica à doutrina das imagens acompanhantes também se direciona a uma ideia central de $P A$. Ali, Husserl explicitava o conceito de número por recurso a dois atos: i) o ato de ligação coletiva (kollektiven 
Essas consequências insustentáveis, em conjunto com sua nova concepção do algoritmo simbólico a ser desenvolvida a partir de 1896, conduzirão Husserl a uma nova compreensão acerca da natureza do signo, colocando em xeque a concepção do signo como mero substituto da coisa. Essa revisão terá como consequência última a elaboração de uma teoria do preenchimento intuitivo responsável por retificar a função que desempenha a intuição na consciência. A intuição será então reconhecida não como aquilo que confere significação ao símbolo, i.e., como aquilo que faz do símbolo algo mais que um rabisco, mas terá uma função completamente diversa - a saber, a função de confirmar aquilo que foi anteriormente pensado, simbolicamente, de modo vazio. $\mathrm{O}$ símbolo será definido agora, portanto, justamente como aquilo que carece de intuitividade - aquilo que é pura e simples intenção vazia de significação. Essa intenção vazia de significação é resultado de uma modificação do caráter de ato (Aktcharacter). Ou seja, ao invés de servir como conteúdo a conferir valor significativo ao símbolo, a intuição servirá como mero fundamento sensível ao ato que doa sentido: "as intenções signitivas têm, ocasionalmente, um apoio (Anhalt) intuitivo, a saber, no aspecto sensível das expressões, mas não possuem, por isso, um conteúdo (Inhalt) intuitivo" (Husserl, 2007, p. 586). Um momento sensível é evidentemente necessário para a constituição do sentido, mas não é ele o que confere sentido, e sim o ato:

a significação reside no caráter de ato doador de sentido, o qual é totalmente diferente segundo o interesse esteja dirigido para o signo sensível ou para o objeto que se torna representável por meio do signo (mesmo que não seja figurado por quaisquer representações da fantasia) (Husserl, 2012, p. 72).

\section{A mudança no regime do signo como condição de possibilidade da análise correlativa}

Eis, assim, a importância histórica desse pequeno tratado de 1890. A análise de suas teses centrais lança nova luz para que se compreenda algumas doutrinas da fenomenologia de $L U$. Vemos, nomeadamente, que a crítica à teoria da economia do pensar como fundamento da lógica nos Prolegômenos é o

Verbindung) de um conjunto (Inbegriff) de coisas e ii) o ato de comparação de determinado conjunto com determinado outro, baseado nas relações de igualdade, mais e menos. Esses dois atos, todavia, são limitados a conjuntos pequenos; como diz a quinta tese defendida por Husserl na Disputation na Universidade de Halle em 1887, "em sentido próprio, mal se pode contar até três" (Husserl, 1970, p. 339). Assim, são necessárias imagens na fantasia para a realização desses atos para quantidades maiores, não passíveis de intuição (1970, p. 14 ss.). 
desdobramento da crítica da Semiótica à insuficiência da explicação psicológica para legitimar logicamente as operações simbólicas; e que a crítica à teoria imagética do signo da $1^{\mathrm{a}}$ Investigação Lógica é uma crítica à própria teoria do signo esposada anteriormente por Husserl para legitimar os substitutos cômodos.

É esta crítica à teoria do signo que nos oferece uma pista da principal mudança que ocorreu na teoria do simbolismo de Husserl entre 1890 e 1901. Trata-se, com efeito, de uma mudança de orientação da investigação. A concepção de símbolo defendida em 1890 dificilmente evita o espectro do representacionalismo clássico de inspiração cartesiano-lockeana, uma vez que a 'aproximação tosca' com a coisa ali propugnada remete, em última instância, à comparação entre representação e coisa. Essa solução representacionalista caminha junto com o projeto da primeira filosofia de Husserl de construção de uma 'linguagem simbólica' paralela ao plano intuitivo e conceitual, o que o conduzirá a conclusões surpreendentes, como a de que o sistema numérico é o responsável por garantir a semelhança estrutural entre os signos numéricos e os números simbolizados e a de que a gramática desempenha papel análogo na linguagem. ${ }^{19}$

O mérito de $L U$ é o de ter lançado as bases para a superação desse representacionalismo de fundo. Assim, o que se conquista com a crítica à teoria imagética do signo é a possibilidade da análise correlativa - sendo esta a posição teórica alternativa à Semiótica que $L U$ tem a oferecer. A teoria da intencionalidade (presente em $L U$ e ausente em Semiótica) permite que o objeto visado possua valor significativo independente da intuição da imagem sensível acompanhante. Assim, antes de partir da oposição absoluta entre símbolo e coisa e perguntar pela possibilidade de 'conexão' entre ambos, perguntar-se-á, em $L U$, pela possibilidade de constituição objetiva da coisa transcendente a partir da imanência dos dados da consciência. Compreende-se, assim, que o objeto não é simplesmente dado, mas é dependente da atividade da consciência. Será esse, doravante, o novo sentido de uma 'investigação lógica', em oposição àquele que partia de modo inquestionável do dualismo símbolo/coisa e buscava esclarecer sua relação de equivalência. Nesse novo sentido, a clarificação da consciência signitiva irá muito além do que a noção de substituição permite

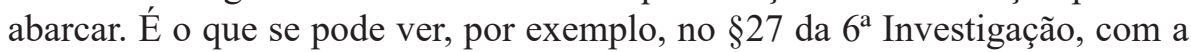
"clarificação definitiva do discurso sobre os modos distintos de referência da consciência a um objeto" (Husserl, 2007, p. 624). Ali, a novidade descritiva da consciência signitiva é trazida à tona de modo claro. A diferença entre 
consciência simbólica e intuição residirá na mudança do caráter de ato das presentações intuitivas de dados sensíveis. A esses dados o ato se dirige para 'interpretar', 'apreender', espiritualizando-os de modo a trazer o objeto à doação. Assim, todo ato tem um conteúdo sensível, e o modo de apreensão desse conteúdo é o que determinará o ato como simbólico ou intuitivo. Esse modo de apreensão Husserl chama forma da apreensão (Aufassungsform): trata-se da relação que vigora entre a matéria do ato (seu 'sentido') e os dados sensíveis. Se esses dados são apreendidos como dessemelhantes ao objeto, temos um ato simbólico; se são apreendidos como semelhantes, temos um ato imaginativo; se são apreendidos como um esboço da própria autoapresentação do objeto, temos um ato perceptivo (2007, p. 621 ss.).

Este último tipo de apreensão (a apreensão perceptiva) é de suma importância, pois mostra que, agora, mesmo a intuição é, em certa medida, um tipo de presunção intencional, i.e., possui também, em algum grau, momentos signitivos. Isto, por sua vez, mostra que o representacionalismo clandestino de 1890 não é definitivamente superado em $L U$. Pelo contrário, como aponta De Boer, "a problemática das $L U$ é a mesma que a do representacionalismo, apesar de todas as aparências do contrário" (De Boer, 1978, p. 430, nota 20). Por isso concluímos que a análise correlativa é ali tornada possível, mas não desenvolvida de modo consequente. O maior empecilho para tal desenvolvimento é justamente a compreensão da intencionalidade linguística como modelo da intencionalidade em geral. ${ }^{20}$ Isso faz com que a doutrina da percepção de $L U$ seja baseada em sua semiótica, partindo do dualismo entre conteúdo e apreensão, o que leva Husserl a esposar "as concepções de percepção como consciência signitiva ou imagética por ele mesmo criticadas" (De Palma, 2008, p. 56). Que se veja, por exemplo, a sua tentativa, na $6^{\mathrm{a}}$ Investigação, de clarificar a "correspondência" entre conteúdo e objeto perceptivo a partir da "semelhança analógica" entre ambos (Husserl, 2007, p. 627). Como enfatiza De Palma, isso só começará a ser superado em definitivo com a distinção entre sínteses ativas e passivas a partir dos anos 20, quando Husserl compreende que "a doação de sentido pressupõe uma experiência sensível já constituída (e não novamente através de uma doação de sentido)" (De Palma, 2008, p. 57).

Ademais, a descrição detalhada dos vários modos de referência da consciência ao objeto também permitirá a elucidação, em $L U$, da relação de substituição requerida para o cálculo meramente simbólico. No $§ 20$ da $1^{\text {a }}$ Investigação, 
Husserl sublinha que, no caso dos signos aritméticos, os signos que substituem não são meros signos, mas signos dotados de uma significação de jogo:

não são os 'simples' signos, no sentido do físico, os signos desligados de toda e qualquer significação, que sub-rogam os signos originários animados de significações aritméticas; ou antes, o que sub-roga os signos significativos aritméticos são os mesmos signos, mas tomados numa certa significação operatória de jogo (Husserl, 2012, p. 75).

Compare-se com a Semiótica, na qual Husserl dizia que, nas inferências (Schließen) simbólicas, "agarramo-nos não a conteúdos próprios e plenos nem a conteúdos parciais sucedâneos, mas simplesmente a nomes ou letras, de modo que não podemos falar eo ipso de um ajuizar ou raciocínios próprios (Husserl, 1970, p. 361, grifo nosso). Numa palavra, o que faltava à Semiótica era o reconhecimento da intencionalidade como constituinte do que é visado pela consciência. No caso de signos substitutos, o que é visado não são meramente nomes ou letras, mas signos dotados de significação operatória e sub-rogante.

Por fim, essa mudança mostra o relevante papel do vazio, da não presença, na consideração fenomenológica da consciência. Consciência é consciência de alguma coisa independentemente do seu teor de plenitude. O objeto pode até mesmo, no limite, não existir. A concebilidade do objeto é independente de que se fantasie qualquer coisa semelhante a ele. Antes, é seu conhecimento que depende de tal figuração na fantasia (ou do aparecimento do objeto mesmo). A Semiótica, com efeito, por não contar com uma analítica prévia dos conteúdos da consciência e por carecer de uma teoria completa da intencionalidade, desconhecia as distinções descritivas responsáveis pela clarificação dos domínios simbólicos e intuitivos, e por isso acabava por confundir a ausência de intuição com a ausência de sentido. Agora, a partir de $L U$, é justamente a clarificação da relação entre o simbólico e o intuitivo e seu papel na constituição do objeto visado que se torna o principal tema, evitando-se, assim, as confusões de que a primeira teoria do signo foi vítima.

Schuhmann, após elaborar uma cuidadosa reconstrução dos textos iniciais de Husserl referentes à representação (incluindo a Semiótica), afirma que um dos maiores exemplos de um tipo de ignava ratio com respeito à filosofia é a:

afirmação de que, desde seu início, a filosofia ocidental foi governada por uma 'métaphysique de présence' que culmina na fenomenologia husserliana, pela razão de que uma doutrina do fenômeno é uma doutrina sobre o que é realmente dado e, portanto, presente. Um estudo cuidadoso dos textos iniciais de Husserl mostra, todavia, que pelo menos sua primeira filosofia é, ao contrário, infestada de ausência (Schuhmann, 2004, p. 277). 
A análise da evolução da teoria do simbolismo da Semiótica até $L U$ oferece fortes argumentos para essa interpretação. Vimos que a mudança operada no pensamento de Husserl com respeito ao pensamento simbólico entre 1890 e 1901 caminha justamente em direção a uma legitimação do pensamento vazio. Ao expor os contrassensos da teoria da representação acompanhante, mostrando que o valor significativo da expressão é função da intenção vazia, Husserl mostra que o característico da consciência é o seu poder de intencionar o objeto na pura ausência. A fenomenologia aparece, assim, como uma filosofia na qual o vazio desempenha um papel constitutivo para a intencionalidade da consciência. ${ }^{21}$

\section{Referências}

BRENTANO, F. "Psychologie vom empirischen Standpunkt”. Erster Band. Hamburg: Felix Meiner Verlag, 1924.

. "Die Lehre vom richtigen Urteil". Hamburg: Felix Meiner Verlag, 1956.

BYRNE, T. "Husserl's Early Semiotics and Number Signs: Philosophy of Arithmetic through the Lens of 'On the Logic of Signs (Semiotic)'". Journal Of The British Society For Phenomenology, Vol. 48, Nr. 4, pp. 287-303, 2017a.

. "Surrogates and Empty Intentions: Husserl's 'On the Logic of Signs' as the Blueprint for his First Logical Investigation". Husserl Studies, Dordrecht, Vol. 33, Nr. 3, pp. 211-227, $2017 \mathrm{~b}$.

. "The Dawn of Husserl's Pure Logical Grammar". Studia Phaenomenologica, Bucharest, Vol. 17, pp. 285-308, 2017c.

"The Evolution of Husserl's Semiotics: The Logical Investigations and its Revisions (1901-1914)". Bulletin d'Analyse Phénoménologique, Vol. XIV, Nr. 5, pp. 1-23, 2018.

D'ANGELO, D. "The foundations of alterity. Husserl on referencing and indicating". Investigaciones Fenomenológicas, Madrid, Vol. 10, pp. 53-71, 2013.

DE BOER, T. "The Development of Husserl's Thought". Den Haag: Martinus Nijhoff, 1978.

DE PALMA, V. "Husserls phänomenologische Semiotik (I. Logische Untersuchung, $\S \S 1$-23)". In: MAYER, Verena (ed.). Logische Untersuchungen - Klassiker Auslegen. Berlin: Akademie Verlag, 2008. pp. 43-59.

ENGLISH, J. "Les recherches logiques et la découverte de l'intentionnalité". In: BENOIST, Jocelyn, VINCENT, Gérard (org.). Lectures de Husserl. Paris: Ellipses, 2010. pp. 77-128.

21 Este artigo é parte de pesquisa de mestrado financiada pela Coordenação de Aperfeiçoamento de Pessoal de Nível Superior (CAPES) entre os anos 2016-2018. Agradeço a Carlos Alberto de Moura, que a orientou, e a dois pareceristas anônimos, pelas ótimas críticas e sugestões realizadas à primeira versão do texto. 
HOPKINS, B. "Authentic and Symbolic Numbers in Husserl's Philosophy of Arithmetic". In: The New Yearbook for Phenomenology and Phenomenological Philosophy, II, 2002. pp. 39-71.

HUSSERL, E. “Aufsätze und Rezensionen (1890-1910)”. Coleção Husserliana, XXII. Den Haag: Martinus Nijhoff, 1979.

. "Da Lógica dos Sinais (Semiótica)". Tradução para o português de António

Fidalgo. [Online] Disponível em http://bocc.ubi.pt/pag/fidalgo-husserl-semiotik.html (Acessado em 04 de março de 2020).

. "Investigações Lógicas: primeiro volume: Prolegômenos à Lógica Pura".

Tradução para o português de Diogo Ferrer. Rio de Janeiro: Forense, 2014.

. "Investigações Lógicas: segundo volume, parte I: investigações para a

fenomenologia e a teoria do conhecimento". Tradução de Pedro M. S. Alves, Carlos Aurélio Morujão. Rio de Janeiro: Forense, 2012.

. "Investigações Lógicas: segundo volume, parte II: investigações para a fenomenologia e a teoria do conhecimento". Tradução de Carlos Aurélio Morujão.

Lisboa: Centro de Filosofia da Universidade de Lisboa, 2007.

. "Logik: Vorlesung 1896. Coleção Husserliana, Materialienbände I". Dordrecht:

Kluwer, 2001.

. "Philosophie der Arithmetik. Mit ergänzenden Texten (1890-1901)". Coleção

Husserliana, XII. Den Haag: Martinus Nijhoff, 1970.

."Persönliche Aufzeichnungen". In: Philosophy and Phenomenological Research,

Vol. 16, pp. 293-302, 1956.

. "Studien zur Arithmetik und Geometrie. Texte Aus Dem Nachlass (18861901)". Coleção Husserliana, XXI. Den Haag: Martinus Nijhoff, 1983.

IERNA, C. "Husserl And The Infinite". Studia Phaenomenologica, Bucharest, Vol. III, Nr. 12, pp. 179-194, 2003.

. "The Beginnings of Husserl's Philosophy, Part 1: From Über den Begriff der Zahl to Philosophie der Arithmetik". In: The New Yearbook for Phenomenology and Phenomenological Philosophy, V, 2005. pp. 1-56.

. "The Brentanist Philosophy of Mathematics in Edmund Husserl's Early Works".

In: CENTRONE, S. (ed.). Essays On Husserl's Logic And Philosophy Of Mathematics. Dordrecht: Springer, 2017. pp. 147-168.

MAJOLINO, C. "Structure de l'indice et équivocité du signe. A l'origine du partage. Anzeige/Ausdruck dans les 'Recherches logiques"”. Histoire Épistémologie Langage, Paris, Vol. 32, Nr. 2, pp. 1-56, 2010.

. "La fabrique du renvoi. Sur quelques thèmes sémiotiques chez le premier Husserl". Paradigmi, Milan, Vol. XXX, Nr. 2, pp. 93-114, 2012.

MILLER, J. P. "Numbers in Presence and Absence: A Study of Husserl's Philosophy of Mathematics". The Hague/Boston/London: Martinus Nijhoff Publishers, 1982.

PORTA, M. "Edmund Husserl: psicologismo, psicologia e fenomenologia". São Paulo: Edições Loyola, 2013. 
SCHUHMAN, K. "Representation in Early Husserl". In: LEIJENHORST, C., STEENBAKKERS, P. (eds.). Karl Schuhmann - Selected Papers on Phenomenology. Kluwer Academic Publishers, 2004. pp. 261-277.

WILLARD, D. 'Husserl's Critique of 'Extensional' Logic: A Logic That Does Not Understand Itself”. Idealistic Studies, Charlottesville, Vol. 9, Nr. 2, pp. 143-164, 1979. . "Logic and the Objectivity of Knowledge: A Study in Husserl's Early Philosophy". Ohio: Ohio University Press, 1984.

. "Husserl on a Logic that Failed". The Philosophical Review, New York, Vol. LXXXIX, Nr. 1, pp. 46-64, 1980.

WILLARD, D. "Translator's Introduction". In: HUSSERL, E. Early Writings in the Philosophy of Logic and Mathematics. Dordrecht: Kluwer Academic Publishers, 1994. pp. VII-XLVIII.

ZUH, D. "How do categorial representations influence everyday intuition? On Husserl's early attempt to grasp the horizontal structure of consciousness". Studia Universitatis Babes Bolyai Philosophia, Cluj-Napoca, Vol. 12, pp. 49-62, 2008.

. "Wogegen wandte sich Husserl 1891? Ein Beitrag zur neueren Rezeption des Verhältnisses von Husserl und Frege". Husserl Studies, Dordrecht, Vol. 28, pp. 95-120, 2012. 